\title{
Desafios éticos e políticos da luta de classes e o mito da democracia racial em Florestan Fernandes
}

\author{
Kátia Regina de Souza Lima \\ Universidade Federal Fluminense (UFF)
}

Desafios éticos e políticos da luta de classes e o mito da democracia racial em Florestan Fernandes Resumo: O artigo tem como objetivo analisar as formulações de Florestan Fernandes sobre o mito da democracia racial brasileira e problematizar os dados recentes sobre desemprego, encarceramento e homicídios no Brasil com base na referida fundamentação teórica. Trata-se de uma análise bibliográfica e documental derivada de projeto de pesquisa desenvolvido em uma rede de pesquisadores da área da Educação. Conclui que um dos desafios éticos e políticos para a ruptura com o capitalismo encontra-se na crítica ao mito da democracia racial que, encobrindo a intolerância racial e mantendo uma superpopulação excedente excluída ou incluída de forma subalternizada no mercado de trabalho, expressa a sua funcionalidade na ordem burguesa, particularmente em um país capitalista dependente como o Brasil.

Palavras-chave: Capitalismo dependente. Luta de Classes. Democracia racial.

\section{Ethical Challenges, the Politics of Class Struggle and the Myth of Racial Democracy in Florestan} Fernandes

Abstract: The objective of this article is to analyze the formulations of Florestan Fernandes about the myth of Brazilian racial democracy and problematize recent data about unemployment, imprisonment and homicides in Brazil, based on this theoretical foundation. It is a bibliographic and document analysis related to a research project undertaken by a network of researchers from the field of education. It concludes that one of the ethical and political challenges to the break with capitalism is criticism of the myth of racial democracy that disguises racial intolerance and maintains a surplus population that is excluded or included in a subaltern form in the labor market. This myth has a functionality in the bourgeois order, particularly in a dependent capitalist country like Brazil.

Keywords: Dependent capitalism. Class struggle. Racial democracy. 


\section{Introdução}

$\mathrm{O}$ artigo apresenta parte das reflexões realizadas em grupo de pesquisa vinculado a um programa de pós-graduação e a uma rede de pesquisadores da área da Educação sobre as particularidades do desenvolvimento do capitalismo no Brasil e tem como objetivo analisar as formulações de Florestan Fernandes sobre o mito da democracia racial brasileira e problematizar os dados recentes sobre desemprego, encarceramento e homicídios no Brasil com base na referida fundamentação teórica.

Florestan Fernandes foi um dos intelectuais militantes que mais contribuiu para a análise crítica do mito da democracia racial brasileira. $\mathrm{O}$ autor inscreve a questão da democracia racial nas particularidades do desenvolvimento do capitalismo no Brasil, isto é, no modo pelo qual a luta de classes se manifesta no capitalismo dependente, a partir dos eixos estruturais - constitutivos da sociedade de classes e dos eixos dinâmicos, que tratam das particularidades do capitalismo dependente e suas manifestações no espaço e no tempo histórico.

Em sua obra, Fernandes examina a inserção capitalista dependente do Brasil na economia mundial inscrita na manifestação histórica e espacial da luta de classes. Dialogando com a tradição marxista, Florestan Fernandes utiliza os conceitos de padrão dual de expropriação do excedente econômico e padrão compósito de hegemonia burguesa como elementos teóricos para examinar o capitalismo dependente e a heteronomia racial a ele associada. Esses elementos fazem com que o padrão de acumulação em sociedades capitalistas dependentes apresente uma racionalidade própria que resultará na revolução burguesa atrasada ou transição não clássica ao capitalismo. A natureza antinacional e antidemocrática da burguesia brasileira será marcada, portanto, pela articulação da subalternização externa com os anacronismos internos, gerando o estabelecimento da sagrada aliança entre capital externo e os senhores rurais.

Desta forma, Florestan Fernandes analisa a acumulação capitalista em países capitalistas dependentes considerando que a ausência de uma acumulação originária suficientemente forte para sustentar um desenvolvimento autônomo gerou a transição das economias coloniais para o capitalismo pela inclusão subalternizada na economia mundial e pela manutenção das bases políticas e socioculturais do sistema colonial associado ao impulso da industrialização e urbanização, caracterizando, assim, o traço ou condição colonial permanente em constante processo de revitalização.

Neste quadro, a mercantilização do trabalho ocorreu com a constituição do mercado de trabalho interno e a transição entre extinção do sistema colonial e a implantação do trabalho livre, vendido como mercadoria, baseado em três fenômenos econômicos, políticos e socioculturais articulados: (a) a arcaização do moderno e a modernização do arcaico, (b) a transição não clássica ao capitalismo conduzida por uma burguesia sem ímpetos revolucionários e (c) a sobrevivência de economias de subsistência e formas extra capitalistas de mercantilização do trabalho, sem permitir que o mercado de trabalho funcionasse segundo os requisitos de uma economia capitalista competitiva.

A análise crítica do mito da democracia racial está inscrita nesta dinâmica mais ampla, isto é, o processo de desagregação do regime escravocrata e senhorial no Brasil foi conduzido sem a garantia de direitos aos negros libertos e fez com que a quase totalidade dos ex-escravos fosse reabsorvida nas áreas rurais em condições análogas às anteriores. Sobre o uso da palavra "negro", Florestan Fernandes (2008, p. 25) considera que

o termo 'preto' sempre foi usado pelo 'branco' para designar o negro e o mulato em São Paulo, mas através de uma imagem estereotipada e sumamente negativa, elaborada socialmente no passado. Os próprios negros e mulatos preferiram, em suas primeiras manifestações de autonomia - através dos movimentos reivindicatórios -, a autodesignação contida na palavra negro.

Assim, a heteronomia racial na sociedade de classes conjugou-se com a heteronomia econômica, política e social, caracterizada pela preservação, na ordem social competitiva, do padrão de relação de dominação do regime escravocrata.

A crítica de Florestan Fernandes ao mito da democracia racial encontra suas bases na análise da manifestação da heteronomia racial sob a aparência de absorção irrestrita do negro na sociedade de classes, assim, o mito omite, até os dias atuais, a persistência de uma diretriz ambivalente de repulsa ao tratamento igualitário do negro e de aparente acatamento de requisitos do regime de classes. Tal problematização evidencia que o mito da democracia racial cria uma aparência democratizante fundada tão somente na igualdade jurídica/ formal forjada na sociedade de classes.

Para recuperarmos estas importantes contribuições de Florestan Fernandes, nos limites deste artigo, estruturamos as reflexões em dois eixos principais. Em um primeiro momento, no item Condição colonial permanente, acumulação capitalista e mercantilização do trabalho retomamos as análises de Fernandes 
sobre o desenvolvimento do capitalismo no Brasil utilizando como referência os conceitos de capitalismo dependente, padrão dual de expropriação do excedente econômico e padrão compósito de hegemonia burguesa.

Tal análise aborda o movimento de continuidades e novidades que marcou a passagem do antigo sistema colonial e a escravidão para a constituição da sociedade de classes e o trabalho livre. Um processo que preservou as funções extra-capitalistas caracterizando uma transição que não implicou em um colapso das antigas estruturas coloniais, mas na preservação das estruturas econômicas e político-sociais sob a égide do sistema colonial, tendo como eixo condutor a exportação de produtos primários associada ao impulso da industrialização e da urbanização e gerando, consequentemente, a articulação de formas heterogêneas de produção que permitem, até os dias atuais, explorar intensamente o trabalho em bases anticapitalistas, semicapitalistas e capitalistas.

No segundo momento, o texto problematiza como a funcionalidade da heteronomia racial e do mito da democracia racial em uma sociedade de classes marcada pelo capitalismo dependente evidencia-se até os dias atuais na manutenção de uma superpopulação excedente excluída ou incluída de forma subalternizada no mercado de trabalho; na aparência de uma igualdade jurídica/formal para todos, negros e brancos, omitindo que a heteronomia racial é um traço constitutivo/estruturante do capitalismo dependente e na resposta do Estado para o enfrentamento da histórica conjugação entre heteronomia econômica, política e social e heteronomia racial: a criminalização, pelo encarceramento e pelo extermínio do trabalhador negro.

Por fim, tais problematizações indicam a necessidade urgente de retomada da obra de Florestan Fernandes para fundamentar a análise crítica e as ações de enfrentamento dos desafios éticos e políticos de articulação das lutas raciais com as lutas classistas na pavimentação do caminho de ruptura com a ordem burguesa.

\section{Condição colonial permanente, acumulação capitalista e mercantilização do trabalho: as bases da crítica ao mito da democracia racial}

Florestan Fernandes analisa o capitalismo no Brasil a partir da forma de integração do país à economia internacional. Uma inserção subordinada aos interesses econômicos e políticos dos países imperialistas e da partilha do mundo gerada pelas transformações na economia mundial. No entanto, essa subordinação não deve ser compreendida como uma imposição de fora, mas articulada aos próprios interesses da burguesia brasileira em reproduzir, internamente, relações de dominação ideológica e exploração econômica, pelas relações patrimonialistas e o uso autocrático das instituições oligárquicas que serão reorganizados para viabilizar a associação das oligarquias com os setores intermediários em formação e com o imperialismo constituindo, como identifica Florestan Fernandes, um padrão compósito de hegemonia burguesa.

Por isso tal padrão de hegemonia burguesa anima uma racionalidade extremamente conservadora, na qual prevalece o intento de proteger a ordem, a propriedade individual, a iniciativa privada, a livre empresa e a associação dependente, vistas como fins instrumentais para a perpetuação do superprivilegiamento econômico, sociocultural e político. (FERNANDES, 1975, p. 108).

Este padrão compósito de hegemonia burguesa faz com que a burguesia associe-se ao imperialismo e, simultaneamente, aos setores mais arcaicos da economia brasileira, configurando o padrão dual de expropriação do excedente econômico. Desta forma, a riqueza produzida coletivamente pelos trabalhadores é repartida entre burguesia internacional e burguesia brasileira, duas faces de um mesmo projeto de dominação.

A relação que é historicamente estabelecida entre padrão compósito de hegemonia burguesa e padrão dual de expropriação do excedente econômico ganha materialidade a partir do traço ou condição colonial permanente definido por Fernandes (1968, p. 26) nos seguintes termos:

Está claro que essa condição se altera continuamente: primeiro, se prende ao antigo sistema colonial; depois se associa ao tipo de colonialismo criado pelo imperialismo das primeiras grandes potências mundiais; na atualidade, vincula-se aos efeitos do capitalismo monopolista na integração da economia internacional. Ela se redefine no curso da história, mas de tal modo que a posição heteronômica da economia do país, em sua estrutura e funcionamento, mantém-se constante. O que varia, porque depende da calibração dos fatores externos envolvidos, é a natureza do nexo da dependência, a polarização da hegemonia e o poder de determinação do núcleo dominante.

Se nas economias capitalistas hegemônicas a apropriação colonial foi um dos fatores geradores da acumulação originária de capital, nas sociedades capitalistas dependentes a transição não-clássica ao capitalis- 
mo ocorreu pela perda constante e crescente de parte substancial do seu excedente econômico. Este é um eixo central da análise de Florestan Fernandes: uma economia de mercado capitalista que crescia com o excedente econômico transferido ou pilhado das economias coloniais, fazendo com que a economia de mercado das sociedades capitalistas dependentes apresentasse dimensões estruturais e dinâmicas determinadas por sua condição heteronômica.

A acumulação capitalista em terras brasileiras não contou com uma acumulação originária suficientemente forte para sustentar um desenvolvimento econômico autônomo. Também não destruiu as estruturas econômicas e sociais arcaicas. A transição inicial das economias coloniais para o capitalismo moderno se fez sob o impulso da inclusão no mercado mundial pela transferência de capitais, técnicas, instituições econômicas e agentes humanos treinados e sem implicar em colapso das antigas estruturas coloniais, na medida em que a comercialização de matéria-prima no mercado mundial exigia a sua persistência.

Este processo resultou em particularidades na mercantilização do trabalho em um país capitalista dependente, caracterizando como foi constituído o mercado de trabalho interno e como se deu a transição entre extinção do sistema colonial e a implantação do trabalho livre, vendido como mercadoria. Florestan Fernandes evidencia que, no Brasil, o mercado de trabalho não funciona segundo os requisitos de uma economia capitalista competitiva, não preenche sequer a função de incluir todos os vendedores reais ou potenciais da força de trabalho, pois a sua mercantilização ocorreu nos marcos da sobrevivência das economias de subsistência e formas extracapitalistas de sua mercantilização.

Neste sentido, o assalariamento é concebido como um privilégio econômico e social na medida em que não está integrado da mesma forma que o capitalismo avançado, pois precisa equilibrar estruturas econômicas em diferentes estágios de evolução econômica, e não exprime equilíbrio articulado do todo, pois as transformações econômicas não foram acompanhadas de transformações substanciais na estrutura social de distribuição de renda dos diferentes estratos da população, expressando, inclusive, a concentração racial da renda, do prestígio e do poder para os brancos.

A organização do trabalho livre caracterizou-se como um processo de transição balanceada para o negro liberto, isto é, "o trabalho livre não contou como uma fonte de libertação do homem e da mulher negros: ele os coloca em competição com os imigrantes em condições desiguais." (FERNANDES, 1989, p. 21).

A Abolição gerou a abundância de mão-de-obra, ainda que não qualificada, em um contexto marcado pela imigração, especialmente vinda da Europa, devidamente qualificada, fazendo com que a ordem competitiva retivesse e agravasse a desigualdade racial pela manifestação ambígua e disfarçada de uma condição real de expropriação e dominação do negro.

Esse mecanismo adaptativo só se tornou possível porque as transformações da estrutura da sociedade, apesar da extinção da escravidão e da universalização do trabalho livre, não afetaram de modo intenso, contínuo e extenso o padrão tradicionalista de acomodação racial e a ordem racial que ele presumia. (FERNANDES, 1972, p. 25).

Fernandes indica que a articulação de formas heterogêneas e anacrônicas de produção preenche historicamente determinada função na economia mundial, permitindo explorar intensamente o trabalho em bases anticapitalistas, semicapitalistas e capitalistas.

Assim, não se trata da sobrevivência de sistemas econômicos pré-capitalistas em economias capitalistas, mas da conjugação de formas desiguais de produção que coexistem. São estruturas econômicas em diferentes estágios de desenvolvimento que são combinadas no interior na sociedade nacional e integradas na economia mundial, pois,

sob o capitalismo dependente, a persistência de formas econômicas arcaicas não é uma função secundária e suplementar. A exploração dessas formas, e sua combinação com outras, mais ou menos modernas e até ultramodernas, fazem parte do 'cálculo capitalista' do agente econômico privilegiado. (FERNANDES, 1968, p. 65).

Problematizando o desenvolvimento das atividades econômicas na transição entre a fase colonial e a emancipação política, Fernandes ressalta que as fases coloniais e neocoloniais alimentaram o processo de acumulação dos países hegemônicos. Com a transição para a emancipação política, o mercado interno passou a incluir mais atividades econômicas, porém, sempre orientadas pelo cálculo capitalista expresso no padrão dual de expropriação do excedente econômico e no padrão compósito de hegemonia burguesa.

Analisando os diferentes padrões de dominação externa na América Latina, Fernandes examina em o livro Capitalismo dependente e classes sociais na América Latina como o terceiro tipo de dominação 
externa, o neocolonialismo, constituiu-se em uma importante fonte de acumulação de capital para os países europeus, especialmente a Inglaterra, fazendo com que a existência das colônias fosse estratégica para o desenvolvimento do capitalismo naqueles países.

Aqui, entretanto, o processo de transição da economia colonial/escravidão para o capitalismo produziu três realidades estruturais: (a) a concentração de renda, do prestígio e do poder nas frações de classe que possuem importância estratégica para o núcleo hegemônico da dominação externa; (b) "a coexistência de estruturas econômicas externas, socioculturais e políticas em diferentes 'épocas históricas', mas interdependentes e igualmente necessárias para a articulação e expansão de toda a economia" (FERNANDES, 1968, p. 20); e (c) a exclusão de uma ampla parcela da população nacional da ordem econômica, social e política existente como um requisito estrutural e dinâmico da estabilidade e do crescimento de todo o sistema capitalista.

É neste quadro político que a questão da heteronomia racial está inscrita. Além de favorecer os interesses externos, essa política revitaliza, sob condições modernas, estruturas de poder e de privilégios arcaicos e antissociais.

Não podemos, portanto, identificar a heteronomia racial apenas como herança colonial, pois, "perde-se de vista o essencial: como a emergência de novas realidades econômicas, sociais e políticas, vinculadas à expropriação capitalista, permitiram a revitalização de atitudes, valores e comportamentos estamentais." (FERNANDES, 1968, p. 39).

As relações de trabalho de origem colonial servem historicamente a sobre-apropriação do excedente econômico e configuram os limites da mercantilização do trabalho nos países capitalistas dependentes (verdadeiros bolsões em relações de trabalho de origem colonial), fazendo com que o arcaico sirva de suporte ao moderno e indique os limites estruturais à universalização da condição operária. Assim,

o capitalismo dependente gera, ao mesmo tempo, o subdesenvolvimento econômico e o subdesenvolvimento social, cultural e político. Em ambos os casos, ele une o arcaico ao moderno e suscita, seja a arcaização do moderno, seja a modernização do arcaico. (FERNANDES, 1968, p. 61).

Esta condição de heteronomia permanente articula o padrão dependente de desenvolvimento e o padrão de mercantilização do trabalho formando as bases do padrão brasileiro de relação racial que tem sua origem nas relações escravistas, mas que é extremamente funcional à ordem burguesa.

\section{O mito da democracia racial: heteronomia racial e heteronomia econômica, política e social no capitalismo dependente}

O padrão brasileiro de relação social ainda hoje dominante articula-se ao padrão brasileiro de relação racial e foi construído por uma sociedade escravista, fazendo com que a distância política, econômica e social entre o negro e o branco não seja abolida, nem reconhecida de modo aberto.

Não se trata de explicar o presente pelo passado, pois passado e presente são reconstruídos de forma interligada, configurando um movimento de continuidades e novidades na medida em que a sociedade de classes lançou suas raízes no anterior sistema escravocrata fazendo com que a situação dos negros fosse recalibrada estrutural e dinamicamente. Aí se encontra o fulcro da questão: identificar como o negro foi incorporado ao sistema de classes nos marcos da universalização do trabalho em nosso país. Para Fernandes (2008, p. 29 e 35),

a desagregação do regime escravocrata e senhorial se operou, no Brasil, sem que se cercasse a destituição dos antigos agentes de trabalho escravo de assistência e garantias que os protegessem na transição para o sistema de trabalho livre [...] em suma, a sociedade brasileira largou o negro ao seu próprio destino, deitando sobre os seus ombros a responsabilidade de se reeducar e de se transformar para corresponder aos novos padrões e ideais de ser humano, criados pelo advento do trabalho livre, do regime republicano e do capitalismo.

A análise da mercantilização do trabalho no Brasil revela a natureza do problema racial brasileiro, ou melhor, como ocorre historicamente a concentração racial da renda, do prestígio social e do poder fazendo com que a classe tenha uma cor determinada no capitalismo dependente.

A heteronomia racial na sociedade de classes evidencia que "o regime extinto não desapareceu por completo após a Abolição. Persistiu na mentalidade, no comportamento e até na organização das relações sociais dos homens, mesmo daqueles que deveriam estar interessados numa subversão total do antigo regime." (FERNANDES, 2008, p. 302 - grifos do autor). 
Aqui encontramos uma contribuição fundamental da obra de Florestan Fernandes: a heteronomia racial associada à heteronomia econômica, política e social é constitutiva do capitalismo dependente e funcional a esta ordem societária. É uma herança da ordem senhorial e escravocrata, mas o capitalismo dependente não tem interesse em romper com esta dupla face de dominação - heteronomia racial e heteronomia econômica, política e social - daí porque permanece até os dias atuais conduzida por um mecanismo de constante revitalização. Florestan Fernandes (2008, p. 303) esclarece com precisão a funcionalidade da heteronomia racial nos dias atuais:

Tomando-se a rede de relações raciais como ela se apresenta em nossos dias, poderia parecer que a desigualdade econômica, social e política entre o 'negro' e o 'branco' fosse fruto do preconceito de cor e da discriminação racial. A análise histórico-sociológica patenteia, porém, que esses mecanismos possuem outra função: a de manter a distância social e o padrão correspondente de isolamento sociocultural, conservados em bloco pela simples perpetuação indefinida de estruturas parciais arcaicas.

Neste sentido, não é a discriminação racial que cria a heteronomia racial, pois essa (a heteronomia racial) foi herdada do antigo sistema colonial e revitalizada a partir dos interesses econômicos, políticos e culturais vigentes na ordem burguesa com o objetivo de defender os interesses e privilégios da burguesia brasileira, parceira da burguesia internacional, na condução do seu padrão compósito de hegemonia e do padrão dual de expropriação do excedente econômico.

É neste contexto que Fernandes identifica como o mito da democracia racial teve origem na passagem da sociedade escravista para a sociedade livre, pois o negro, nessa passagem, foi mantido nos limites de uma economia de subsistência. O mito encobriu a persistência do passado nas dimensões econômicas, políticas e sociais da sociedade de classes, configurando, desta forma, um padrão tradicional brasileiro de relação racial que articula heteronomia econômica e heteronomia de raça e opera uma segregação sutil e dissimulada.

A crítica ao mito da democracia racial encontra suas raízes na desarticulação do regime escravocrata senhorial e nas transformações mais avançadas da sociedade competitiva e está fundamentada nos "mecanismos de mobilidade social seletiva, numa linha ultra-individualista, e de aceitação e compensação dos 'negros' e 'mulatos' que funcionam como a exceção que confirma a regra." (FERNANDES, 1972, p. 11).

O mito tem a função de esconder a realidade. Fernandes $(1989$, p. 17) considera que

O mito - não os fatos - permite ignorar a enormidade da preservação de desigualdades tão extremas e desumanas como são as desigualdades raciais no Brasil; dissimula que as vantagens relativas 'sobem' nunca 'descem' - na pirâmide racial; e confunde as percepções e as explicações - mesmo as que têm como 'críticas', mas não vão ao fundo das coisas - das realidades cotidianas.

Analisando os aspectos éticos e políticos do dilema racial brasileiro, Florestan Fernandes encontra suas raízes no impasse gerado, por um lado, pela necessidade da mercantilização do trabalho livre e da defesa da igualdade e da liberdade na ordem competitiva e, por outro, pelos comportamentos efetivos de subalternização dos negros a partir da desagregação da sociedade escravagista e da formação da própria sociedade de classes em um país capitalista dependente, como o Brasil, marcada por uma mentalidade conservadora mantida até os dias atuais exatamente porque é funcional ao capitalismo. Essa mentalidade não constitui um desvio de rota ou uma excrescência, mas é um elemento estrutural e dinâmico constitutivo do capitalismo dependente que tem em suas bases o constante processo de revitalização do arcaico no conjunto das relações sociais.

Para Fernandes, o dilema social e racial é eminentemente ético e político, apresentando raízes econômicas, sociais e culturais, na medida em que as fronteiras raciais não desapareceram com a Abolição. "Doutro lado, como a economia de trabalho livre se organizou sobre um patamar pré-capitalista e colonial, seria lamentável se ignorássemos como as determinações de raças se inseriram e afetaram as determinações de classes." (FERNANDES, 1972, p. 260).

A sociedade de classes surge e se desenvolve no Brasil dependendo da continuidade das estruturas econômicas e sociais do sistema colonial. A descolonização não significou o fim do monopólio da riqueza, do prestígio social e do poder, indicando os limites da revolução dentro da ordem e da transição não clássica para o capitalismo.

A persistência, sob várias formas, de dominação externa e a expansão interna do capitalismo impõe a continuidade de modelos verdadeiramente coloniais de apropriação e de expropriação econômica, aos quais deve corresponder, necessariamente, uma extrema concentração permanente da riqueza, no tope, e o uso pacífico ou violento de técnicas autocráticas de opressão e de repressão. (FERNANDES, 1972, p. 263-264). 
Neste contexto, Florestan Fernandes considera que o mito da democracia racial é uma distorção criada desde o sistema colonial diante da inclusão de mestiços nas famílias brancas, fazendo com que a miscigenação aparecesse como elemento de mobilidade social dos negros e omitindo o fato de que a miscigenação era construtora da estratificação social, oferecendo ao mestiço um lugar determinado social e economicamente pelo mundo dos brancos. O que a miscigenação proporcionou não foi a ascensão social dos negros, mas o fortalecimento da dominação racial, na medida em que trouxe o negro para a adaptação ao horizonte cultural hegemônico, ainda que nos limites da concentração racial da renda, do prestígio social e do poder. Assim, "criou-se e difundiu-se a imagem do 'negro de alma branca' - o protótipo do negro leal, devotado ao seu senhor, à sua família e à própria ordem social existente.” (FERNANDES, 1972, p. 27).

É importante recuperarmos as análises de Florestan Fernandes sobre o elemento estrutural da situação racial brasileira a partir de duas dimensões organicamente vinculadas. Por um lado, a impossibilidade de o capitalismo dependente absorver os diferentes setores da população como consequência de um processo seletivo de mercantilização do trabalho que excluiu ou incluiu de forma subalternizada os libertos. A transição não clássica ao capitalismo, nos marcos do padrão compósito de hegemonia burguesa e do padrão dual de expropriação do excedente econômico, não foi capaz de consolidar e expandir a ordem social competitiva nos limites das exigências da própria ordem burguesa, alcançando apenas os segmentos brancos da população historicamente dominantes.

Por outro, a "persistência do passado"(FERNANDES, 1972, p. 83), isto é, a revitalização da mentalidade herdada do sistema colonial de que o liberto, ainda que sob novas ordenações jurídicas e políticas (homem livre), fosse considerado como um ser nas fronteiras da animalidade fez com que a segregação disfarçada se constituísse como eixo estrutural e dinâmico da sociedade de classes.

Este é o busílis do dilema racial brasileiro: a associação da condição social, pelos fatores econômicos e políticos que o determinam, com a condição racial, pela relação estabelecida com o liberto que, ao longo do desenvolvimento do capitalismo no Brasil, constituiu-se em elemento chave para a manutenção de um imenso exército de reserva para as tarefas consi-

Não podemos, portanto, identificar a heteronomia racial apenas como herança colonial, pois, "perde-se de vista o essencial: como a emergência de novas realidades econômicas, sociais e políticas, vinculadas à expropriação capitalista, permitiram a revitalização de atitudes, valores e comportamentos estamentais." (FERNANDES, 1968, p. 39). deradas desqualificadas para os brancos, fazendo com que o padrão assimétrico de relação racial fosse transferido, em sua quase totalidade, para uma nova situação histórico-social marcada por uma nova fase do padrão externo de dominação caracterizado pelo capitalismo dependente.

Com a ordem social competitiva, o discurso hegemônico advoga que a liberdade e igualdade foram concedidas ao negro e se esse não construiu condições econômicas e sociais para viabilizar sua ascensão social, a responsabilidade não é da ordem competitiva, mas da incapacidade do negro em enquadra-se na nova ordem societária. Neste sentido, o dilema racial brasileiro evidencia-se pelo processo que Fernandes (1972, p. 85) identificou como a existência de

dois mundos humanos contínuos, mas com estanques e com destinos opostos. O mundo dos brancos foi profundamente alterado pelo surto econômico e pelo desenvolvimento social, ligados à produção [...] $\mathrm{o}$ mundo dos negros ficou praticamente à margem desses processos sócio-econômicos, como se ele estivesse dentro dos muros da cidade, mas não participassem coletivamente de sua vida econômica, social e política.

Se recuperarmos esta perspectiva política e teórico-metodológica de Florestan Fernandes como um eixo estruturante da questão racial no Brasil, evidencia-se um profícuo instrumental para análise dos seus desafios éticos e políticos, hoje, em nosso país.

$\mathrm{Na}$ atualidade, a interface entre heteronomia econômica, política e social e heteronomia racial manifesta-se na manutenção de uma superpopulação excedente excluída ou incluída de forma subalternizada no mercado de trabalho; na aparência de uma igualdade jurídica/formal para todos, negros e brancos, omitindo que a heteronomia racial é um traço constitutivo/estruturante do capitalismo dependente e na resposta do Estado 
para o enfrentamento da histórica conjugação entre heteronomia econômica, política e social e heteronomia racial: a criminalização do trabalhador negro pelo encarceramento e pelo extermínio.

Dados da Pesquisa Nacional por Amostra de Domicílios Contínua do IBGE (Algumas características da força de trabalho por cor ou raça) evidenciam que a população total do Brasil no $4^{\circ}$ Trimestre de 2016 foi estimada em 206, 1 bilhões de pessoas, sendo 43,8\% declaradas brancas e 55,4\% declaradas negras $(8,2 \%)$ ou pardas $(47,2 \%)$, conforme definição do referido Instituto. (BRASIL, 2016, p. 3).

Apesar deste contingente, o mapeamento da população considerada ocupada no Brasil em 2016 é revelador das desigualdades econômicas e raciais na atualidade. Quando analisado por cor ou raça, o rendimento dos pardos e dos negros corresponde respectivamente a $55,6 \%$ e $54,9 \%$ do rendimento dos brancos. Em sentido inverso, no mesmo período ( $4^{\circ}$ trimestre de 2016), o contingente de população desocupada (sem vínculo de emprego) subiu para 12,3 milhões de pessoas e a participação de pardos $(52,7 \%)$ e negros $(11 \%)$ desocupados foi de $63,7 \%$ neste período, enquanto a dos brancos foi de 35,6\%. (BRASIL, 2016).

Outra face da heteronomia racial associada à heteronomia econômica, política e social pode ser evidenciada nos dados apresentados pelo Mapa do Encarceramento - Os jovens do Brasil, lançado em 2015. Segundo o referido relatório, no período entre 2005 e 2012 ocorreu um crescimento de $74 \%$ da população prisional brasileira, em números absolutos, sendo que $69 \%$ em regime fechado. Do total da população prisional brasileira em 2012, 54,8\% da população encarcerada era formada por jovens, segundo a Lei $\mathrm{n}^{\circ} 12.852 / 2013$, ou seja, tinha menos que 29 anos de idade. (BRASIL, 2015, p 25, 28 e 31).

Em relação ao perfil da população prisional segundo cor/raça, o relatório afirma que

Diante dos dados sobre cor/raça verifica-se que, em todo o período analisado, existiram mais negros presos no Brasil do que brancos. Em números absolutos: em 2005 havia 92.052 negros presos e 62.569 brancos, ou seja, considerando-se a parcela da população carcerária para a qual havia informação sobre cor disponível, 58,4\% era negra. Já em 2012 havia 292.242 negros presos e 175.536 brancos, ou seja, 60,8\% da população prisional era negra. Constata-se assim que quanto mais cresce a população prisional no país, mais cresce o número de negros encarcerados. O crescimento do encarceramento é mais impulsionado pela prisão de pessoas negras do que brancas. (BRASIL, 2015, p. 33).

Outros dados evidenciam a relação entre heteronomia racial e heteronomia econômica, política e social na atualidade, como aqueles apresentados no Mapa da Violência. Homicídios por Armas de Fogo no Brasil organizado por Julio J. Waiselfisz. Segundo o autor, o número total de vítimas fatais por arma de fogo no ano de 2014 foi de 44.861, sendo 42.291 por homicídio. Desse número, 94,4\% da média nacional são homens jovens, na faixa entre 15 e 29 anos de idade. (WAISELFISZ, 2015).

No que diz respeito à questão racial, entre 2003 e 2014 houve uma redução de $26,1 \%$ na taxa de homicídios por arma de fogo na população branca, entretanto, no mesmo período, ocorreu um aumento de 46,9\% na taxa de homicídios por arma de fogo na população negra. Em 2014, 29.813 negros foram assassinados por arma de fogo no Brasil. (WAISELFISZ, 2015, p. 55).

$\mathrm{O}$ exame dos dados recentes acima indicados demonstra a atualidade das reflexões de Fernandes quando afirmava que a desigualdade racial manteve-se inalterável, ainda que renovando constantemente as condições materiais, éticas e políticas para a sua reprodução incessante.

A desagregação do regime escravocrata não rompeu com a heteronomia racial, pois o capitalismo dependente foi capaz de absorver a heteronomia racial e associá-la à heteronomia econômica, política e social. Neste quadro, está preservada até os dias atuais "a concentração racial da renda, do prestígio social e do poder mais representativo de uma 'sociedade de castas' que de uma 'sociedade de classes'." (FERNANDES, 1972, p. 97).

Florestan Fernandes indica, desta forma, as origens sociais remotas do preconceito e da descriminação racial no Brasil e, simultaneamente, denuncia o traço estruturante que, sistematicamente reatualizado, permanece como determinante da questão racial no país. Preconceito e discriminação vinculam-se fundamentalmente com a estrutura da sociedade de classes que, recuperando os traços coloniais permanentes e apresentandoos sob nova roupagem (igualdade jurídica formal entre brancos e negros fundada no mito da democracia racial), buscam omitir um paralelismo entre raça, renda, prestígio e poder social.

\section{Considerações Finais}

A interlocução com Florestan Fernandes indica que a articulação das lutas raciais e classistas são desafios éticos e políticos a serem enfrentados na pavimentação do caminho de ruptura com a ordem burgue- 
sa. A articulação entre heteronomia racial e heteronomia econômica não é um subproduto histórico de um Brasil colonial, não constitui um erro de percurso ou ainda a persistência de um traço a ser corrigido, mas um fenômeno apropriado pelo capitalismo dependente em seu movimento de conformação ou de criminalização, pelo encarceramento ou pelo extermínio, de uma massa de trabalhadores que não são incorporados sequer aos desígnios da ordem burguesa.

O dilema racial brasileiro possui um caráter estrutural e indica como ocorre historicamente a concentração racial da renda, do prestígio social e do poder, fazendo com que a classe tenha uma cor determinada no capitalismo dependente. Para enfrentá-lo é necessária a ruptura com a ordem societária que o estimula a partir da associação entre heteronomia racial e heteronomia econômica, política e social.

O mito da democracia racial mascara estes elementos estruturais e dinâmicos constitutivos da própria inserção capitalista dependente do Brasil na economia mundial e da forma/conteúdo como ocorreu a mercantilização da força de trabalho no país.

A igualdade jurídica/formal objetiva o apagamento das contradições acirradas na ordem competitiva, fazendo com que sejam estabelecidas relações de tolerância mínima e, majoritariamente, de intolerância em relação aos trabalhadores negros, como indicam os dados recentes acima apresentados sobre a manutenção de uma superpopulação excedente excluída ou incluída de forma subalternizada no mercado de trabalho; o encarceramento e o extermínio de jovens negros no Brasil.

A funcionalidade da heteronomia racial é, portanto, evidente na ordem burguesa, associando historicamente barreiras raciais e econômicas para os trabalhadores negros. A análise crítica do mito da democracia racial cria as bases para apreensão de que

Classe e raça se fortalecem reciprocamente e combinam forças centrífugas à ordem existente [...] Nas lutas dentro da ordem, a solidariedade de classe não pode deixar frestas [...] Quer dizer que a raça é uma formação social que não pode ser negligenciada na estratégia da luta de classes e de transformação dentro da ordem ou contra a ordem. (FERNANDES, 1989, p. 62-64).

O capitalismo dependente está constituído historicamente sob essa associação e romper com a heteronomia econômica, política e social e a heteronomia racial é, portanto, parte dos desafios éticos e das ações políticas para ruptura com o próprio capitalismo.

\section{Referências bibliográficas}

BRASIL. Instituto Brasileiro de Geografia e Estatística. Indicadores IBGE. Pesquisa Nacional por Amostra de Domicílios Contínua. Algumas características da força de trabalho por raça ou cor. 2016. Disponível em: <ftp://ftp.ibge.gov.br/Trabalho_e_Rendimento/ Pesquisa_Nacional_por_Amostra_de_Domicilios_continua/Trimestral/Caracteristicas_da_forca_de_trabalho_por_cor_ou_raca/ Algumas_caracteristicas_da_forca_de_trabalho_por_cor_ou_raca_2016_04_trimestre.pdf $>$. Acesso em: 07 mar. 2017.

. Secretaria-Geral da Presidência da República. Secretaria Nacional de Juventude. Mapa do Encarceramento: os jovens do Brasil.

Brasília: Presidência da República, 2015. Disponível em: <http://juventude.gov.br/articles/participatorio/0010/1092/ Mapa_do_Encarceramento_-_Os_jovens_do_brasil.pdf>. Acesso em: 07 mar. 2017.

FERNANDES, F. Capitalismo dependente e classes sociais na América Latina. 2. ed. Rio de Janeiro: Zahar, 1975. . A Integração do Negro na Sociedade de Classes. Volume I. Ensaio de Interpretação Sociológica. 5. ed. São Paulo: Globo, 2008. . O negro no mundo dos brancos. São Paulo: Difusão Européia do Livro, 1972.

Significado do protesto negro. São Paulo: Cortez: Autores Associados, 1989.

. Sociedade de classes e subdesenvolvimento. Rio de Janeiro: Zahar, 1968.

WAISELFISZ, J. J. Mapa da Violência 2016: homicídios por armas de fogo no Brasil. [Brasília]: Flacso Brasil, 2015. Disponível em: $<$ http://www.mapadaviolencia.org.br/pdf2016/Mapa2016_armas_web.pdf>. Acesso em: 07 mar. 2017.

\section{Kátia Regina de Souza Lima}

katiaslima@globo.com

Doutorado em Educação pelo Programa de Pós-Graduação em Educação da Universidade Federal Fluminense (UFF)

Professora Associada da Escola de Serviço Social e do Programa de Pós-Graduação em Serviço Social e Desenvolvimento Regional da Universidade Federal Fluminense (UFF) 
UFF

Rua Prof. Marcos Waldemar de Freitas Reis, s/n ${ }^{\circ}$

Campus do Gragoatá - Bloco E - São Domingos

Niterói - Rio de Janeiro - Brasil

CEP: 24.210-201 